\title{
RESEARCH AND REPORTS
}

\section{Insights Gained from Analysis of Citations in Clinical Laboratory Science}

FRANCES A. DELWICHE

\begin{abstract}
This study describes a citation analysis conducted on publications in Clinical Laboratory Science from 20102014. References were gathered and sorted according to format and publication date; for references to journal articles, the journal title was also recorded. At $71.0 \%$, the journal article was found to be the most frequently cited format. Over $54 \%$ of the references were five years old or less, and over $91 \%$ were from the last two decades. A total of 815 unique journal titles were cited. The 22 most frequently cited journals provided approximately one-third of the references, while over $85 \%$ of the journals were cited three times or less. The most frequently cited journals were drawn from general medicine, pathology/laboratory medicine, the preclinical sciences, and general science. Results of the study can be used by faculty, students, practitioners, and researchers to support scholarship and research, and to advance the long-term goals of the profession.
\end{abstract}

ABBREVIATIONS: ASP - Academic Search Premier, CINAHL - Cumulative Index to Nursing and Allied Health Literature, PNAHS - ProQuest Nursing $\&$ Allied Health Source, SCIE - Science Citation Index Expanded

INDEX TERMS: Bibliometrics, Databases, bibliographic, Periodicals as Topic

Clin Lab Sci 2016;29(1):21-27

Frances A. Delwiche, M.L.I.S, MT(ASCP), Dana Medical Library, University of Vermont, Burlington, VT

Address for Correspondence: Frances A. Delwiche, Library Associate Professor, M.L.I.S, MT(ASCP), Dana Medical Library, University of Vermont, 81 Colchester Avenue, Burlington, VT 05405, 802-6564423, frances.delwiche@uvm.edu

\section{INTRODUCTION}

Bibliometrics may be described as "The use of statistical methods in the analysis of a body of literature to reveal the historical development of subject fields and patterns of authorship, publication, and use." ${ }^{1}$ One of the most heavily used methods in bibliometrics is citation analysis. The first article that can be identified as a citation analysis, published in 1927, was an analysis of the references from all articles published over the course of one year in the Journal of the American Chemical Society. ${ }^{2}$ Since then, hundreds of citation analyses in a wide range of subject areas have appeared in the scholarly literature. Depending upon their focus and methodology, citation analyses may provide insights about scholarly productivity, either at the author level or at the journal level. When used in combination with other bibliometric measures, citation analyses can provide insights into the nature and character of the literature of a discipline or subject area.

The scholarly literature contains few bibliometric studies specific to clinical laboratory science. In 2003, a citation analysis was conducted using references found in three years (1998-2000) of articles published in three separate clinical laboratory science journals. ${ }^{3}$ The goal of that study was to generate information about the literature of clinical laboratory science, which would guide librarians in building journal collections for their patrons in this field. Whereas the findings have indeed proven to be useful to collection development librarians, they have also proven to be uniquely informative to educators, students, practitioners, and researchers in the discipline itself. As that study is now over twelve years old, and was conducted just as the Internet was coming into prominence as a publishing venue, an analysis reflecting this changed landscape is clearly warranted.

\section{METHODS}

The methodology employed by this study was based on that described by Schloman, ${ }^{4}$ but deviated from it in that it analyzed references from only one journal, 
Clinical Laboratory Science, rather than from multiple journals.

The first step of the study was to gather all references cited by all articles published in Clinical Laboratory Science for five years, from 2010 through 2014, including the Supplements. The references were manually entered into a Microsoft EXCEL ${ }^{\oplus}$ database, with the following information collected for each reference: year, volume, and issue of Clinical Laboratory Science; article number; subject of the article; reference number; reference format; and publication date.

References were categorized as one of four formats, ranked in the following order: Journal Article, Government Information, Book, or Miscellaneous. References that could be categorized as more than one format were entered as the higher-ranking format. The title of the journal was recorded for all references to journal articles. References from journals that had undergone one or more title changes in its history were collated under the most recent title. Government Information included any material published by a national, state, or local government entity, except for government-published journals. Examples of Government Information included laws and regulations, legal cases, statistics, reports, press releases, and consumer health websites such as MEDLINEPlus. The Miscellaneous category included materials such as newspapers, newsletters, posters and presentations, theses and dissertations, internal reports, package inserts, and personal communications. Miscellaneous references were sub-categorized as deriving from Internet websites, versus any other means. Dates for Internet websites, when not clearly stated, were assumed to be the year the reference was accessed.

References were further categorized according to the subject of the article from which they were obtained. The following subject categories were used: Cell \& Molecular Biology, Chemistry, Education, Hematology, Immunohematology, Microbiology, and Professional Issues. Articles that did not fit into one of these subject areas were classified as Other.

Upon entry of all data, the total number of references was tallied, both for each year and overall. The references were sorted according to format, publication date, and subject. For references to journal articles, the journal titles were sorted according to the frequency with which they were cited. This enabled creation of a ranked list of journal titles which placed the most frequently cited journal at the top of the list, followed by the second most frequently cited journal, and so on. In addition, the five most frequently cited journals for each of the subject categories were identified.

The final step of the study was to compare coverage of the 22 most frequently cited journals by seven popular bibliographic databases. Two key databases in the biomedical and health sciences, MEDLINE (US National Library of Medicine) and The Cumulative Index to Nursing \& Allied Health, commonly referred as CINAHL (EBSCO), were automatically included in the study. Two multi-disciplinary science databases, Scopus (Elsevier) and Science Citation Index Expanded, a portion of the Web of Science (Thomson Reuters), were also included, as was Academic Search Premier (EBSCO), a multi-disciplinary database of broad scope that is widely used in academia. Rounding out the group was BIOSIS Previews (Thomson Reuters), a database that focuses on research in the life sciences, and ProQuest Nursing \& Allied Health Source (ProQuest), which provides coverage similar to CINAHL.

\section{RESULTS}

From 2010 through 2014, twenty-three issues of Clinical Laboratory Science were published, including three Supplements. From these, a total of 3452 references were collected from 203 articles. Each issue included an average of 8.6 articles with one or more references, and each article had an average of 17.2 references.

An examination of the format of the references revealed that $71.0 \%(2451 / 3452)$ of the references were in the Journal Article category, making this by far the most frequently cited format. Miscellaneous formats came in at a distant second, at 13.2\% (470/3452), followed by Books, with $10.2 \%(350 / 3452)$ of the total, and lastly, Government Information, with 5.2\% (181/3452). Of the Miscellaneous references, $79.4 \%$ (373/470) were accessed through Internet websites, while $20.6 \%$ (97/470) were accessed through other means.

The publication dates of the references for each of the five years were analyzed separately and in composite. In 
the composite analysis, it was found that $9.0 \%$ (309/3452) of the references were dated the same year the article was published; 45.1\% (1556/3452) were from 1 to 5 years old; and $76.0 \%(2624 / 3452)$ were ten years old or less. Moreover, 91.4\% (3156/3452) of the references were from the last two decades, leaving only $8.5 \%(292 / 3452)$ that were more than twenty years old. The date could not be determined for $0.1 \%$ (4/3452) of the references. (Table 1)

\begin{tabular}{|c|c|c|c|c|c|c|}
\hline & 2010 & 2011 & 2012 & 2013 & 2014 & Total \\
\hline Current Year & $77(9.2 \%)$ & $35(5.5 \%)$ & $74(9.4 \%)$ & $31(5.4 \%)$ & $92(14.9 \%)$ & $309(9.0 \%)$ \\
\hline $1-5$ yrs old & $397(47.2 \%)$ & $298(46.9 \%)$ & $350(44.5 \%)$ & $288(50.4 \%)$ & $223(36.2 \%)$ & $1556(45.1 \%)$ \\
\hline $6-10$ yrs old & $190(22.6 \%)$ & $141(22.2 \%)$ & $160(20.3 \%)$ & $135(23.6 \%)$ & $133(21.6 \%)$ & $759(22.0 \%)$ \\
\hline $11-20$ yrs old & $119(14.1 \%)$ & $106(16.7 \%)$ & $137(17.4 \%)$ & $83(14.5 \%)$ & $87(14.1 \%)$ & $532(15.4 \%)$ \\
\hline $21-30$ yrs old & $43(5.1 \%)$ & $32(5.0 \%)$ & $27(3.4 \%)$ & $19(3.3 \%)$ & $29(4.7 \%)$ & $150(4.3 \%)$ \\
\hline $31-40$ yrs old & $9(1.1 \%)$ & $11(1.7 \%)$ & $12(1.5 \%)$ & $9(1.6 \%)$ & $18(2.9 \%)$ & $59(1.7 \%)$ \\
\hline $41-50$ yrs old & $3(0.4 \%)$ & $5(0.8 \%)$ & $9(1.2 \%)$ & $1(0.2 \%)$ & $12(2.0 \%)$ & $30(0.9 \%)$ \\
\hline$>50$ yrs old & $2(0.2 \%)$ & $6(0.9 \%)$ & $17(2.2 \%)$ & $6(1.0 \%)$ & $22(3.6 \%)$ & $53(1.5 \%)$ \\
\hline Unknown & $1(0.1 \%)$ & $2(0.3 \%)$ & $1(0.1 \%)$ & $0(0 \%)$ & $0(0 \%)$ & $4(0.1 \%)$ \\
\hline TOTAL & $841(100.0 \%)$ & $636(100.0 \%)$ & $787(100.0 \%)$ & $572(100.0 \%)$ & $616(100.0 \%)$ & $3452(100.0 \%)$ \\
\hline
\end{tabular}

With regard to subject area, the largest number of references was from articles categorized as Microbiology, accounting for $26.3 \%$ (908/3452) of the total. In descending order, this was followed by articles categorized as Hematology at $16.9 \%$ (582/3452), Education at $15.1 \%(520 / 3452)$, Chemistry at $11.9 \%$ (410/3452), Professional Issues at 10.6\% (367/3452), and Cell \& Molecular Biology at 8.4\% (291/3452). The fewest references were from articles categorized as Immunohematology, with $1.8 \%(62 / 3452)$ of the total. The remaining $9.0 \%(312 / 3452)$ of the references were determined to be on subjects outside these areas, or were on multiple subjects.

As described previously, for all journal article references, the name of the journal was also captured. This made it possible to count the total number of unique journal titles cited, and, most importantly, to sort the journal titles according to the frequency with which they were cited. The end result was a rank-ordered list of journals, with the most frequently cited journal listed at the top of the list, and the least frequently cited journals listed last.

A total of 815 journals were cited at least once over the course of the five-year period. The most frequently cited journal was Clinical Laboratory Science, with a total of 179 references. The second most frequently cited journal was the Journal of Clinical Microbiology, followed by the New England Journal of Medicine, Blood, and Clinical Infectious Diseases. Upon review of the list of journals, a precipitous drop-off in the number of citations that each journal received was noted. For example, whereas the top-ranked journal was cited 179 times, the $10^{\text {th }}$ ranked journal was cited only 27 times, and the 100th ranked journal was cited only 4 times. Furthermore, $85.4 \%(696 / 815)$ of the journals were found to have been cited three times or fewer, and $64.5 \%(526 / 815)$ were cited only once over the course of the entire five years (Table 2).

The importance of this distribution pattern can be illustrated through a simple mathematical calculation. Once the journals were sorted according to frequency of citation, the total number of references from journal articles was divided into three roughly equal groups. It then become evident that a relatively small group of 22 journals produced approximately the same number of references as a second, larger group of 140 journals, and as a third, very large group of 653 journals. The journals in the first group were cited between 19 and 179 times; those in the second group were cited between 3 and 19 times; and those in the third group were cited 3 times or fewer (Table 3 ).

At this point, a well-known bibliometric tool can be brought to bear. In 1950, with the publication of his slim volume entitled Documentation, Samuel B. Bradford described the phenomenon that has come to be popularly known as "Bradford's Law of Scattering".5 According to Bradford, for a given subject, relevant articles will be found most frequently in a core group of journals; somewhat less frequently in a larger group of less-closely related journals; and much less frequently in 


\begin{tabular}{|c|c|c|c|c|c|c|c|c|c|}
\hline \# & Journal Title & $\begin{array}{c}\# \\
\text { Refs } \\
\end{array}$ & MEDLINE & SCOPUS & SCIE & BIOSIS & ASP & CINAHL & PNAHS \\
\hline 1 & Clin Lab Sci & 179 & $\mathrm{Y}$ & Y & $\mathrm{N}$ & $\mathrm{N}$ & $\mathrm{N}$ & Y & Y \\
\hline 2 & J Clin Microbiol & 61 & Y & $\mathrm{Y}$ & $\mathrm{Y}$ & $\mathrm{N}$ & $\mathrm{N}$ & $\mathrm{N}$ & $\mathrm{N}$ \\
\hline 3 & New Engl J Med & 59 & $\mathrm{Y}$ & Y & Y & Y & Y & Y & $\mathrm{Y}$ \\
\hline 4 & Blood & 49 & $\mathrm{Y}$ & Y & Y & Y & Y & $\mathrm{N}$ & $\mathrm{N}$ \\
\hline 5 & Clin Infect Dis & 47 & Y & Y & Y & $\mathrm{N}$ & Y & $\mathrm{N}$ & $\mathrm{N}$ \\
\hline 6 & Clin Chem & 41 & Y & Y & Y & $\mathrm{Y}$ & $\mathrm{N}$ & $\mathrm{N}$ & $\mathrm{Y}$ \\
\hline 7 & JAMA & 32 & Y & Y & Y & Y & $\mathrm{Y}$ & Y & $\mathrm{Y}$ \\
\hline 8 & Am J Clin Pathol & 29 & Y & Y & Y & Y & Y & $\mathrm{N}$ & $\mathrm{Y}$ \\
\hline 9 & Lab Med & 28 & Y & Y & Y & $\mathrm{N}$ & Y & Y & $\mathrm{Y}$ \\
\hline 10 & Nature & 27 & Y & Y & Y & $\mathrm{Y}$ & Y & $\mathrm{N}$ & $\mathrm{Y}$ \\
\hline 11 & Ann Intern Med & 25 & Y & Y & Y & Y & Y & Y & $\mathrm{Y}$ \\
\hline 12 & $\begin{array}{l}\text { Infect Control } \\
\text { Hosp Epidemiol }\end{array}$ & 24 & $\mathrm{Y}$ & $\mathrm{Y}$ & $\mathrm{Y}$ & $\mathrm{Y}$ & $\mathrm{N}$ & $\mathrm{Y}$ & $\mathrm{N}$ \\
\hline 13 & $\begin{array}{l}\text { Am J Infect } \\
\text { Control }\end{array}$ & 23 & $\mathrm{Y}$ & $\mathrm{Y}$ & $\mathrm{Y}$ & $\mathrm{Y}$ & $\mathrm{N}$ & $\mathrm{Y}$ & $\mathrm{N}$ \\
\hline 14 & $\begin{array}{l}\text { Arch Pathol Lab } \\
\text { Med }\end{array}$ & 23 & $\mathrm{Y}$ & $\mathrm{Y}$ & Y & $\mathrm{N}$ & Y & $\mathrm{Y}$ & $\mathrm{Y}$ \\
\hline 15 & Emerg Infect Dis & 22 & $\mathrm{Y}$ & $\mathrm{Y}$ & $\mathrm{Y}$ & $\mathrm{Y}$ & $\mathrm{Y}$ & $\mathrm{N}$ & $\mathrm{N}$ \\
\hline 16 & $\begin{array}{l}\text { Semin Thromb } \\
\text { Hemost }\end{array}$ & 22 & Y & Y & Y & Y & $\mathrm{Y}$ & $\mathrm{N}$ & $\mathrm{N}$ \\
\hline 17 & $\begin{array}{l}\text { Proc Natl Acad Sci } \\
\text { U S A }\end{array}$ & 21 & Y & Y & Y & Y & Y & $\mathrm{N}$ & $\mathrm{N}$ \\
\hline 18 & Thromb Haemost & 21 & $\mathrm{Y}$ & Y & $\mathrm{Y}$ & Y & $\mathrm{N}$ & $\mathrm{N}$ & $\mathrm{N}$ \\
\hline 19 & BMJ & 20 & $\mathrm{Y}$ & $\mathrm{Y}$ & $\mathrm{Y}$ & $\mathrm{Y}$ & Y & $\mathrm{Y}$ & $\mathrm{Y}$ \\
\hline 20 & Chest & 20 & Y & Y & Y & Y & Y & Y & $\mathrm{N}$ \\
\hline 21 & Science & 20 & Y & Y & $\mathrm{Y}$ & Y & Y & $\mathrm{N}$ & $\mathrm{N}$ \\
\hline 22 & J Allied Health & 19 & Y & Y & $\mathrm{N}$ & $\mathrm{N}$ & $\mathrm{N}$ & Y & Y \\
\hline & Total Coverage & & $\begin{array}{c}22 / 22 \\
(100 \%)\end{array}$ & $\begin{array}{c}22 / 22 \\
(100 \%)\end{array}$ & $\begin{array}{l}20 / 22 \\
(91 \%)\end{array}$ & $\begin{array}{l}16 / 22 \\
(73 \%)\end{array}$ & $\begin{array}{l}15 / 22 \\
(68 \%)\end{array}$ & $\begin{array}{l}11 / 22 \\
(50 \%)\end{array}$ & $\begin{array}{l}11 / 22 \\
(50 \%)\end{array}$ \\
\hline \multicolumn{10}{|c|}{$\begin{array}{l}\text { MEDLINE = MEDLINE, United States National Library of Medicine } \\
\text { CINAHL = Cumulative Index to Nursing \& Allied Health, EBSCO Publishing } \\
\text { SCIE = Science Citation Index Expanded, Thomson Reuters } \\
\text { ASP = Academic Search Premier, EBSCO Publishing } \\
\text { BIOSIS = BIOSIS Previews, Thomson Reuters } \\
\text { PNAHS = ProQuest Nursing \& Allied Health Source, ProQuest }\end{array}$} \\
\hline
\end{tabular}

a vast number of journals, many of which only rarely contain a relevant article. Because the present study was publication-based rather than subject-based, Bradford's Law cannot be directly applied here. Nevertheless, the general concept can be used to illustrate the magnitude of the contribution that a small, core group of journals makes to a subject area's knowledgebase, and conversely the extraordinarily large number of journals that, taken together, constitute the entire knowledgebase for that subject.

Once the ranked list of cited journals was obtained, the indexing coverage of the top 22 journals by seven bibliographic databases was determined. (Refer to Table 2.) Two databases, MEDLINE and SCOPUS, provided $100 \%$ coverage of the top 22 journals, and Science Citation Index Expanded provided over 90\% coverage. Coverage provided by BIOSIS Previews was somewhat lower, at 73\%, followed by Academic Search Premier at

\begin{tabular}{|c|c|c|}
\hline Group & Cited Journals & Cited Journal References \\
\hline 1 & $22(2.7 \%)$ & $812(33.1 \%)$ \\
\hline 2 & $140(17.2 \%)$ & 817 (33.3\%) \\
\hline 3 & $653(80.1 \%)$ & $822(33.6 \%)$ \\
\hline TOTAL & $815(100.0 \%)$ & $2451(100.0 \%)$ \\
\hline
\end{tabular}




\begin{tabular}{|c|c|c|c|c|}
\hline Subject & $\begin{array}{l}\text { Total number } \\
\text { refs }\end{array}$ & $\begin{array}{l}\text { \# of refs from } \\
\text { journal articles }\end{array}$ & $\begin{array}{l}\text { Five most frequently cited journals, with times } \\
\text { cited }\end{array}$ & \\
\hline \multirow[t]{5}{*}{ Microbiology } & $908 / 3452(26.3 \%)$ & $653 / 908$ & J Clin Microbiol & 59 \\
\hline & & $(71.9 \%)$ & Clin Infect Dis & 45 \\
\hline & & & Infect Control Hosp Epidemiol & 23 \\
\hline & & & Emerg Infect Dis & 21 \\
\hline & & & J Hosp Infect & 19 \\
\hline \multirow[t]{5}{*}{ Hematology } & $582 / 3452(16.9 \%)$ & $473 / 582$ & Blood & 33 \\
\hline & & $(81.3 \%)$ & Semin Thromb Hemost & 22 \\
\hline & & & Thromb Haemost & 20 \\
\hline & & & Am J Clin Pathol & 19 \\
\hline & & & Eur J Cancer & 15 \\
\hline \multirow[t]{5}{*}{ Education } & $520 / 3452(15.1 \%)$ & $325 / 520$ & Clin Lab Sci & 70 \\
\hline & & $(62.5 \%)$ & J Allied Health & 18 \\
\hline & & & Anat Rec & 11 \\
\hline & & & Lab Med & 10 \\
\hline & & & Anat Sci Educ & 7 \\
\hline \multirow[t]{5}{*}{ Chemistry } & $410 / 3452(11.9 \%)$ & $335 / 410$ & Clin Chem & 23 \\
\hline & & $(81.7 \%)$ & New Engl J Med & 14 \\
\hline & & & Diabetes Care & 10 \\
\hline & & & Circulation & 9 \\
\hline & & & $\begin{array}{l}\text { J Am Coll Cardiol (3-way tie with J Biol Chem and } \\
\text { Nature) }\end{array}$ & 7 \\
\hline \multirow[t]{5}{*}{ Professional } & $367 / 3452(10.6 \%)$ & $250 / 367$ & Clin Lab Sci & 85 \\
\hline & & $(68.1 \%)$ & Med Lab Observer & 12 \\
\hline & & & Lab Med & 11 \\
\hline & & & Women Higher Educ & 8 \\
\hline & & & J Assoc Genet Technol & 7 \\
\hline \multirow[t]{5}{*}{ Miscellaneous } & $312 / 3452(9.0 \%)$ & $170 / 312$ & Am J Infect Control & 13 \\
\hline & & $(54.5 \%)$ & Arch Pathol Lab Med & 13 \\
\hline & & & BMJ & 9 \\
\hline & & & Clin Chem & 8 \\
\hline & & & Clin Lab Sci & 7 \\
\hline \multirow[t]{5}{*}{ Cell/Molec Biol } & $291 / 3452(8.4 \%)$ & $202 / 291$ & Cancer Res & 17 \\
\hline & & $(69.4 \%)$ & Nature & 14 \\
\hline & & & Blood & 12 \\
\hline & & & Proc Natl Acad Sci U S A & 8 \\
\hline & & & J Clin Oncol & 7 \\
\hline \multirow[t]{5}{*}{ Immunohematology } & $62 / 3452(1.8 \%)$ & $43 / 62$ & Transfusion & 9 \\
\hline & & $(69.4 \%)$ & Immunohematology & 6 \\
\hline & & & Blood & 3 \\
\hline & & & Artif Cells Blood Substit Immobil Biotechnol & 2 \\
\hline & & & Proc Natl Acad Sci U S A & 2 \\
\hline TOTAL & $3452(100.0 \%)$ & - & & \\
\hline
\end{tabular}

$68 \%$. Finally, both nursing \& allied health-specific databases, CINAHL and PNAHS, provided coverage of $50 \%$ of the 22 top-cited journals. In addition to the composite list of journals, a list of the five most frequently cited journals was obtained for each of the eight subject areas (Table 4).

\section{DISCUSSION}

An examination of the publication dates of the references indicates a clear preference by authors writing in Clinical Laboratory Science for the most current literature available. This comes as no surprise, given the rapid pace of technological development in the field. The high percentage of references dating from the current year may be a reflection of today's accelerated publication cycle, and an increased utilization of and access to the Internet. 
Despite the rise of informal means of communication, especially online, this study suggests that the formal journal article remains the gold standard for scholarly communication in clinical laboratory science. However, at $71.0 \%$ of the total, this represents a substantial drop from the results of the 2003 study in which $83.5 \%$ of the references cited in Clinical Laboratory Science were from journal articles. ${ }^{3}$ The use of books remained nearly the same in both studies, but the use of information obtained from Internet web sites saw a dramatic increase from $0.8 \%$ of the total in the 2003 study to $10.8 \%(373 / 3452)$ of the total in the current study. Similarly, the use of government information increased substantially, from $1.4 \%$ to $5.2 \%$. This may be a reflection of the transition by government bodies from the former print publishing model to a more costeffective online publishing model as a vehicle for distributing information to the general public.

A review of the list of top-cited journals, reveals that authors writing in Clinical Laboratory Science drew heavily from the literature of general medicine, the medical specialties, especially pathology/laboratory medicine, the pre-clinical sciences, and general science. However, consistent with the principles of Bradford's Law of Scattering, authors also referred to the literature from many disparate fields. Among the least frequently cited journals were titles such as the Journal of Dental Hygiene, Journal of Insect Science, Microgravity Science \& Technology, Sport Journal, and Teaching Music, each of which were cited only once.

Despite being the journal title that received the largest number of citations, the rate of journal self-citation in this study was relatively low, at 5.2\% (179/3452). This was well below the rate for all 5876 journals covered by the 2002 Journal Citation Reports, for which a mean of $12.41 \%$ and a median of $9.04 \%$ was reported. ${ }^{6}$

Coverage of the 22 top-cited journals by the major indexing services also provided useful insights. Although no database can be expected to index every journal, MEDLINE is an excellent database with which to begin a literature search in clinical laboratory science. A reflection of its strong focus on both the clinical and pre-clinical sciences, MEDLINE provided 100\% coverage of the top-ranked journal titles. It can be expected to index many, though probably not all, of the remaining journals in the list. In addition to its excellent coverage, MEDLINE has the advantage of being freely accessible worldwide to anyone with an Internet connection. Scopus and Science Citation Index Expanded can also be expected to provide coverage of many of the journals in the list, but unlike MEDLINE, neither is free, and not all institutions will provide access to them.

In contrast to MEDLINE which has its primary focus on biomedicine, especially clinical medicine, BIOSIS Previews provides proportionately greater coverage of pre-clinical and life sciences research, with proportionately less coverage of the clinical disciplines. This may result in the discovery of articles that have been published in journals that are not indexed by MEDLINE. Furthermore, BIOSIS Previews also indexes non-journal materials, such as scientific conferences, patents, and book chapters, which are not indexed by MEDLINE. BIOSIS Previews thus fills an important niche, demonstrating that each bibliographic database plays a valuable role in scientific discourse by indexing a unique set of sources.

The multi-disciplinary database Academic Search Premier is very popular, easy to search, and widely available on many academic campuses, making it an attractive choice, especially for undergraduate students. Finally, as indexes of the allied health literature, both CINAHL and PNAHS provide reasonably good coverage of the field, although they provide less comprehensive coverage of the medical specialties and pre-clinical sciences that provide the underpinnings for this field.

The information from the ranked lists of journals can be used by faculty, students, practitioners, and researchers in medical laboratory science in a variety of ways. When assigning research papers, literature reviews, capstone projects, and other writing-based activities, faculty may draw students' attention to the overall top-ranked journals, as well as those in each subject area, as a way of guiding them toward the richest sources of information. Practitioners may wish to monitor the Table of Contents of recent issues of the top-ranked journals as a way of keeping up with new developments. Scholars may wish to submit manuscripts to the more frequently cited journals as a way to maximize exposure for their research. Finally, the findings of this study may help scholars and researchers 
to appreciate the importance of conducting comprehensive searches across multiple databases in order to find articles from journals that only occasionally contribute a relevant article.

\section{LIMITATIONS}

As this study analyzed the references from just one journal, the raw data was, by necessity, influenced by the type of manuscripts considered and accepted for publication by this journal, which was in turn influenced by the journal's mission and editorial policies. Nonetheless, Clinical Laboratory Science is one of the primary scholarly journals for clinical laboratory science and is published by one of the major professional organizations in the field. By scrutinizing the references cited by authors writing in this journal, useful insights can be gained regarding the nature of the literature which these authors used as their knowledgebase.

The internal validity of this study is dependent upon the accuracy with which the contributing authors compiled their reference lists, as well as the accuracy with which the references were entered into the EXCEL database. For some articles, it was difficult to determine the subject area, possibly resulting in misclassification. Some subject areas had relatively small numbers of references, making the ranked list for those areas less reliable. The publication dates for some references, in particular those from Internet websites, were occasionally difficult to determine or absent altogether. Journal title changes were occasionally difficult to identify, possibly resulting in errors in compiling the ranked journal list.

\section{CONCLUSION}

One of the hallmarks of a profession is that it possesses a specialized body of knowledge that is unique to that group. $^{7-8}$ Through this analysis of references cited by authors writing in Clinical Laboratory Science, members of the profession stand to gain valuable clues as to the nature of the knowledgebase of the profession as a whole. The study's findings will contribute to the ability of clinical laboratory scientists to search the scholarly biomedical literature, an essential skill for finding the evidence to support practice decisions. Furthermore, there has been an increasing call from within the profession to nurture a greater culture of scholarship and research, ${ }^{9-11}$ and for the development of advanced degree options in clinical laboratory science. ${ }^{11-}$ ${ }^{12}$ In order to achieve success in these endeavors, it will become imperative that scholars and researchers have a solid understanding of the body of knowledge which defines their profession, as well as the knowledge and skills with which to access it efficiently and competently.

\section{REFERENCES}

1. Young H, Belanger T. The ALA glossary of library and information science. Chicago: American Library Association; 1983.

2. Andrés A. Measuring academic research: how to undertake a bibliometric study. Oxford: Chandos; 2009.

3. Delwiche FA. Mapping the literature of clinical laboratory science. J Med Libr Assoc. 2003;91(3):303-10.

4. Schloman BF. Mapping the literature of allied health: project overview. Bull Med Libr Assoc. 1997;85(3):271-7.

5. Bradford SC. Documentation. Washington, DC: Public Affairs Press; 1950

6. McVeigh ME. Journal self-citation in the Journal Citation Reports - Science Edition (2002) [Internet]. Toronto: Thomson Reuters; 2003 [cited 2015 Feb 27]. http://wokinfo.com/essays/ journal-self-citation-jcr/ .

7. French JG. The last piece in the puzzle-the importance of publishing and establishing the professional status of medical radiation technologists. Can J Med Radiat Technol. 2007;38(3):23-6.

8. Scope of practice. Clin Lab Sci. 2013;26(1):4-7.

9. Rohde RE, Falleur DM, Redwine GD, Patterson TL. Growing our own: teaching and doing research in CLS. Clin Lab Sci. 2010;23(3 Suppl):3-11-18.

10. Saleh SM, Hamed KM. Preparing CLS professionals to be consumers and producers of research. Clin Lab Sci. 2010;23(3 Suppl):3-19-23.

11. Heuertz RM. Research in the Medical Laboratory Science curriculum. Clin Lab Sci. 2011;24(4 Suppl):4-54-60.

12. Russell B, Kraj B, Pretlow L, Ranne A, Leibach EK. Evidence based practice and advanced competencies in a MHS-CLS program. Clin Lab Sci. 2011;24(4Suppl):4-47-53. 